\title{
Factitial Hyperthyroidism: A Diagnostic Challenge
}

\author{
Riyadh Hammamy $^{1}$, Dr Khalid Farooqui ${ }^{1}$, and Mohamed Shariff ${ }^{1}$ \\ ${ }^{1}$ Hamad Medical Corporation
}

September 25, 2021

\begin{abstract}
Thyrotoxicosis factitia is not very uncommon. There is a high likelihood of it being missed in our day-to-day clinical practice which can lead not only to significant patient morbidity but also put burden on health-care resources. We report a case masquerading as refractory thyrotoxicosis diagnosed to have uncontrolled hyperthyroidism.
\end{abstract}

\section{Introduction:}

Thyrotoxicosis factitia is most often caused by excessive ingestion of thyroid hormones which could be intentional or inadvertent (contamination of dietary supplements). Possible causes of hyperthyroidism are Graves disease, toxic thyroid adenoma, multinodular goiter, some forms of subacute or chronic thyroiditis and rare pituitary thyroid-stimulating hormone (TSH) producing tumors, other causes can be extra thyroid in origin, may occur in ovaric strumma and thyrotoxicosis factitia, due to intentional or accidental excessive intake of pharmaceutical thyroid hormone preparations or thyroxin-contaminated ground beef [1].

The possibility of thyrotoxicosis factitia should be considered in patients who have features of hyperthyroidism and psychiatric disturbance without any evidence of goitre or proptosis and the results of thyroid function are conflicting [2].

This case report draws attention to one such instance wherein there was an apparent thyrotoxicosis due to secretive ingestion of levothyroxine [2]. Our patient attended to outpatient clinic during the last five year period with clinical features suggestive of hyperthyroidism, and a combination of thyroid function tests indicating that she was taking exogenous thyroxine.

\section{Case report:}

A 43-year-old female patient referred from gynecology department to control her hyperthyroidism as she was scheduled for hysterectomy due to large multiple uterine fibroids, she reported to have type 2 diabetes mellitus over the last six years and has been on metformin $1 \mathrm{gm}$ twice daily and liraglutide $1.8 \mathrm{mg}$ once daily, she was also diagnosed to have hyperthyroidism over the last five years and was on carbimazole 80 mg daily. Clinically she looks very thin and emaciated with BMI of 17, no exophthalmos and no goiter, with unremarkable systemic examination. After reviewing her file we found that she underwent multiple plastic surgeries of her breast and abdomen (mammoplasty, abdominoplasty and liposuction), and she has also undergone gastric balloon followed by sleeve gastrectomy to reduce her weight as she was obese six years back with a BMI of 31, we have found that her TSH was suppressed all the times over the last five years although she claimed taking her carbimazole regularly, Thyroid radioactive iodine uptake (RAIU) scan done twice showed low uptake favoring a diagnosis of thyroiditis, in addition to this her diabetes history was inconsistent with her investigations, serial glucose and HB A1c results all were normal even before starting the anti-diabetic medications. we have also noticed that some vital imaging and tests were missing like thyroid ultrasound, serum thyroglobulin and thyroid receptor antibody. After thorough investigations [Table1] and imaging, we excluded diabetes and hyperthyroidism and a diagnosis of thyrotoxicosis factitia 
was considered and the patient was confronted and eventually confessed that she is taking dietary supplement containing levothyroxine and liraglutide since long time to reduce weight and she is still not happy with her weight and was eager to lose more.

Ultrasound Thyroid: was normal and no significant pathology. Repeated blood investigation after two months showed significant improvement [Table 2].

\section{Table 1:}

\section{Initial laboratory results;}

\begin{tabular}{lll}
\hline Labs & Results & Normal range \\
\hline WBC & 6700 & $4000-10000$ \\
$\mathrm{HB} \%$ & $11.4 \mathrm{gm} / \mathrm{dl}$ & $12.0-15.0 \mathrm{gm} / \mathrm{dl}$ \\
Platelets & 362,000 & $150,000-400,000$ \\
Urea & $6.2 \mathrm{mmol} / \mathrm{L}$ & $2.5-7.8 \mathrm{mmol} / \mathrm{L}$ \\
Creatinine & $72 \mathrm{umol} / \mathrm{L}$ & $44-80 \mathrm{umol} / \mathrm{L}$ \\
Sodium & $138 \mathrm{mmol} / \mathrm{L}$ & $133-146 \mathrm{mmol} / \mathrm{L}$ \\
Potassium & $2.5 \mathrm{mmol} / \mathrm{l}$ & $3.5-5.3 \mathrm{mmol} / \mathrm{L}$ \\
Magnesium & $0.76 \mathrm{mmol} / \mathrm{l}$ & $0.7-1.0 \mathrm{mmol} / \mathrm{L}$ \\
Total Protien & $71 \mathrm{gm} / \mathrm{L}$ & $60-80 \mathrm{gm} / \mathrm{L}$ \\
Albumin & $33 \mathrm{gm} / \mathrm{L}$ & $35-50 \mathrm{gm} / \mathrm{L}$ \\
ALT & $9 \mathrm{U} / \mathrm{L}$ & $0.0-33 \mathrm{U} / \mathrm{L}$ \\
AST & $12 \mathrm{U} / \mathrm{L}$ & $0.0-32 \mathrm{U} / \mathrm{L}$ \\
TSH & $<0.01 \mathrm{mIU} / 1$ & $0.3-4.2 \mathrm{mIU} / \mathrm{l}$ \\
FT4 & $35.5 \mathrm{pmol} / \mathrm{l}$ & $11.6-21 \mathrm{pmol} / 1$ \\
FT3 & $18.6 \mathrm{pmol} / \mathrm{l}$ & $3.7-6.4 \mathrm{pmol} / \mathrm{l}$ \\
TPO Antibodies & Negative & \\
TRAB Antibodies & Negative & \\
Thyroglobulin & Negative & \\
\hline
\end{tabular}

Table 2: Follow up laboratory results two months after stopping her herbal medicine that contain thyroxine;

\begin{tabular}{lll}
\hline Labs & Results & Normal Range \\
\hline TSH & $0.2 \mathrm{mIU} / \mathrm{l}$ & $0.3-4.2 \mathrm{mIU} / 1$ \\
FT3 & $6.0 \mathrm{pmol} / 1$ & $3.7-6.4 \mathrm{pmol} / 1$ \\
FT4 & $14.0 \mathrm{pmol} / 1$ & $11.6-21 \mathrm{pmol} / 1$ \\
$\mathrm{~K}+$ & $3.8 \mathrm{mmol} / \mathrm{L}$ & $3.5-5.3 \mathrm{mmol} / \mathrm{L}$ \\
\hline
\end{tabular}

\section{Discussion:}

Thyrotoxicosis factitia is the term used to describe hyperthyroidism due to excessive intake of exogenous thyroxine, it can be intentional for therapeutic suppression of TSH in cases of thyroid malignancy and in some cases to treat obesity [3], or inadvertent due to contamination of supplements Like weight reducing supplements which claimed to be herbal but contained an appreciable amount of both $\mathrm{T} 3$ and $\mathrm{T} 4$ or animal thyroid tissue [4].

It is also seen in individuals with a background of underlying psychiatric disease, for cosmetic reasons or accidental ingestion of high quantity of thyroid hormones, most often seen in paramedical personnel who have access to thyroid hormone or in patients for whom thyroid hormone medication has been prescribed in the past [5]. 
The diagnosis of factitial hyperthyroidism in the absence of preexisting disease of the thyroid is certain when there are typical thyrotoxic manifestations like abdominal cramps, diarrhea, weight loss, heat intolerance, together with thyroid atrophy and hypofunction which is evidenced by the subnormal values of RAIU. Infiltrative ophthalmopathy is never a feature but the eye signs are obvious. Serum TSH levels are suppressed and serum T4 is high in most of the cases unless the patient is taking T3, in such situation the T4 might be subnormal. Serum T3 concentrations is high in either case. Unlike true thyrotoxicosis the presence of low, rather than elevated, values of serum thyroglobulin $(\mathrm{Tg})$ is a clear indication that the thyrotoxicosis results from exogenous hormone and not from thyroid hyperfunction.

Other clinical complications commonly include skeleton system (osteoporosis) and the cardiovascular system (tachyarrhythmias mainly atrial fibrillation) which are the major target tissues adversely affected by chronic use of exogenous thyroxine, however, abnormalities in other systems have been reported.

A patient taking excessive amounts of levothyroxine and concealing this from her doctors can pose a difficult diagnostic problem.

In terms of published literature, Braustein et al reported five cases of unintentional thyrotoxicosis factitia where all of them ingested levothyroxine pills as they believed that this hormone is non-toxic substance that would help them to lose weight [6].

Hamburger Thyrotoxicosis was a rare form of exogenous thyrotoxicosis which resulted when the grounded beef contained thyroid tissue. This condition disappeared when there was a change in slaughtering practices. The possibility of such a condition needs to be considered in the event of an epidemic exogenous thyrotoxicosis $[7]$.

In general thyrotoxicosis factitia is thought to be caused by the secret ingestion of excessive amount of thyroxine by neuropsychiatric patients [2]. The diagnosis of thyrotoxicosis factitia depends on careful history to determine the use of exogenous thyroxine or dietary supplements, a detailed examination to exclude goiter and exophthalmos, thyroid image with normal ultra-sound and low thyroid iodine uptake and laboratory findings with suppressed TSH, high FT4 and FT3, with negative thyroid receptor antibody and low thyroglobulin [8].

In our case since the patient was referred for control of hyperthyroidism from gynecology unit as patient was supposed to go for elective resection of multiple uterine fibroids. With detailed history, careful reviewing of patient previous files and labs along with focused clinical examination, there was a high index of clinical suspicion about the exogenous use of levothyroxine and there were missing investigations like ultrasound thyroid and thyroglobulin levels. Since the patient was diagnosed as hyperthyroidism five years ago with suppressed TSH on carbimazole maximum dose at present and still her TSH was suppressed along with missing investigations. Given the patients inclination towards cosmetic looks, leading question were put to the patient about the use of any weight reducing medications, and to our surprise she was taking herbal medications for weight loss with levothyroxine as one of its content. We report this case as it was misdiagnosed as thyrotoxicosis for five years and initiated on carbimazole, This

case highlights the importance of detailed history taking \& medication reconciliation which is vital in such a diagnostic dilemma.

\section{References:}

1. Meurisse M, Gollogly L, Degauque C, et al. Iatrogenic thyrotoxicosis: causal circumstances, pathophysiology, and principles of treatment-review of the literature. World J Surg 2000; 24: 1377-85. doi: $10.1007 / \mathrm{s} 002680010228$.

2. Harvey RF. Thyroxine "addicts". Br Med J 1973; 2: 35-6. doi: 10.1136/bmj .2.5857.35 .

3. Cohen JH 3rd, Ingbar SH, Braverman LE. Thyrotoxicosis due to ingestion of excess thyroid hormone. Endocr Rev. 1989;10(2):113. doi: 10.1210/edrv-10 -2-113.

4. Kang GY, Parks JR, Fileta B, et al. Thyroxine and triiodothyronine content in commercially available thyroid health supplements. Thyroid. 2013 Oct;23(10):1233-7. Epub 2013 Sep 14. DOI: 
10.1089/thy.2013.0101.

5. Williams text book of endocrinology $14^{\text {th }}$ Edition 2020,section III, Page no.402. http://ISBN: 9780323555968 .

6. Braunstein GD, Koblin R, Sugawara M, et al. Unintentional thyrotoxicosis factitial due to a diet pill. West J Med 1986;145:388-91. PMC1306951.

7. Hedberg CW, Fishbein DB, Janssen RS, et al. An outbreak of thyrotoxicosis caused by the consumption of bovine thyroid gland in ground beef. N Engl J Med. 1987;316(16):993-998. doi: 10.1056/NEJM198704163161605.

8. Mariotti S, Martino E, Cupini C, et al. Low serum thyroglobulin as a clue to the diagnosis of thyrotoxicosis factitia. N Engl J Med. 1982;307(7):410. DOI: 10.1056/NEJM198208123070705.

Acknowledgment: None

Conflict of Interest: The authors declare no conflict of Interest 